Article

\title{
Synthesis of Zeolite A from Metakaolin and Its Application in the Adsorption of Cationic Dyes
}

\author{
Priscila Martins Pereira ${ }^{1}$, Breno Freitas Ferreira ${ }^{1}$, Nathalia Paula Oliveira ${ }^{1}$, \\ Eduardo José Nassar ${ }^{1}$, Katia Jorge Ciuffi ${ }^{1}$, Miguel Angel Vicente ${ }^{2, *}$ (i), Raquel Trujillano ${ }^{2}$, \\ Vicente Rives $^{2}{ }^{\mathbb{D}}$, Antonio Gil $^{3}{ }^{\mathbb{D}}$, , Sophia Korili ${ }^{3}$ and Emerson Henrique de Faria ${ }^{1, *}$ \\ 1 Grupo de Pesquisas em Materiais Lamelares Híbridos (GPMatLam), Universidade de Franca, \\ Av. Dr. Armando Salles Oliveira, CEP 14404-600, Franca 201, Brazil; priscilapereira@hotmail.com (P.M.P.); \\ brenofreitasferreira@gmail.com (B.F.F.); nathpaulaoliveira@gmail.com (N.P.O.); \\ ejnassar@unifran.br (E.J.N.); katia.ciuffi@unifran.edu.br (K.J.C.) \\ 2 GIR-QUESCAT-Departamento de Química Inorgánica, Universidad de Salamanca, 37008 Salamanca, Spain; \\ rakel@usal.es (R.T.); vrives@usal.es (V.R.) \\ 3 INAMAT-Departamento de Química Aplicada, Universidad Pública de Navarra, 31006 Pamplona, Spain; \\ andoni@unavarra.es (A.G.); sofia.korili@unavarra.es (S.K.) \\ * Correspondence: mavicente@usal.es (M.A.V.); emerson.faria@unifran.edu.br (E.H.d.F.); \\ Tel.: +55-16-3711-8969 (E.H.d.F.)
}

Received: 19 March 2018; Accepted: 9 April 2018; Published: 11 April 2018

Featured Application: Zeolites obtained from natural clays by simple methods are potential efficient adsorbents of cationic dyes. Zeolites obtained from natural clays by simple methods may be used as efficient adsorbents of cationic dyes.

\begin{abstract}
The present work reports the synthesis of zeolites from two metakaolins, one derived from the white kaolin and the other derived from the red kaolin, found in a deposit in the city of São Simão (Brazil). The metakaolins were prepared by calcination of the kaolins at $600{ }^{\circ} \mathrm{C}$; zeolite A was obtained after alkali treatment of the metakaolins with $\mathrm{NaOH}$. The resulting solids were characterized by powder X-ray diffraction, thermal analysis, scanning electron microscopy, and nitrogen adsorption/desorption at $-196^{\circ} \mathrm{C}$, which confirmed formation of zeolite A. The zeolites were applied as adsorbents to remove methylene blue, safranine, and malachite green from aqueous solutions. The zeolites displayed high adsorption capacity within short times (between one and five minutes); $q_{t}$ was $0.96 \mathrm{mg} / \mathrm{g}$. The equilibrium study showed that the zeolites had higher adsorption capacity for malachite green $\left(q_{e}=55.00 \mathrm{mg} / \mathrm{g}\right)$ than for the other two cationic dyes, and that the Langmuir isotherm was the model that best explained the adsorption mechanism.
\end{abstract}

Keywords: kaolin; metakaolin; zeolite A; cationic dye adsorption

\section{Introduction}

Industries such as dyes, textiles, paper, pharmaceuticals, and plastics generate a considerable amount of wastewater. Dyes are the primary contaminants recognized in wastewater due to their color. Approximately $15 \%$ of the total world production of dyes is lost during the dyeing process. Consequently, a large quantity of dyes is released into textile effluents [1]. Removing these contaminants from industrial wastewaters before effluents are discharged into the aquatic environment is obviously necessary. Various methods, such as biological processes [2], ultrasound [3], active carbon adsorption [4], ozone treatment [5], coagulation/flocculation [6], and ion exchange resin [7,8] and ion exchange membrane adsorption methods [9], have been investigated in an attempt to remediate dye-containing wastewaters. However, these methods are not always efficient and economical enough, 
so new alternative technologies that rely on low-cost materials are mandatory to solve the issues related to dye-containing wastewaters [10].

In this sense, natural clays have been modified to prepare several types of materials, including nanotubes [11], metakaolins [12], and zeolites [12]. The final material depends on the parent clay and on the treatment to which the clay is submitted. Zeolites obtained from kaolin are highlighted as advantageous, inexpensive materials for this purpose. Zeolites can be prepared by treating kaolin with alkaline compounds. The reactivity of the clay increases if it is calcined at medium temperatures (ca. $600{ }^{\circ} \mathrm{C}$ ), to form metakaolins in the intermediate step [13].

Numerous researchers have revisited the presence of transition metal cations within the zeolite structure in recent years because these metal cations impart new properties to the solid, making them applicable for catalytic purposes or for environmental remediation through adsorption of various contaminants. For instance, Fe(III) cations, which very often exist as impurities in many zeolites, have been introduced into synthetic zeolites structurally or via cation exchange [14]. The presence of transition metal cations within the structure of a solid matrix can alter the crystallinity of the solid and even hinder clay conversion to zeolites in some cases [15].

Zeolites synthesized from several natural sources, such as clays and fly ash, are very important porous and selective adsorbents and display high ion exchange capacities. Table 1 lists some literature results on the preparation methods and on the conventional uses of zeolites.

Table 1. Literature data on the use of zeolites prepared from several sources as adsorbents of dyes from aqueous solutions.

\begin{tabular}{cccc}
\hline Zeolite Type & Adsorbate & Adsorbed Amount (mg/g) & Reference \\
\hline LTA (synthetic from fly ash) & Acid fuchsin & 40.64 & {$[16]$} \\
\hline Zeolite (clinoptilolite-rich mineral) & Acid orange 95 & 3.4 & {$[17]$} \\
\hline \multirow{2}{*}{ Zeolite (clinoptilolite-rich mineral) } & Acid blue 25 & 0.1 & \multirow{2}{*}{ Basic blue 9 } \\
& Basic violet 3 & 82 & \\
\hline \multirow{2}{*}{ Zeolite (clinoptilolite mineral) } & Methylene blue & 98 & \\
& Methyl red & 12 & \\
\hline \multirow{2}{*}{ Modified zeolite } & Methylene blue & 83 & \\
& Methyl red & 10 & \\
\hline
\end{tabular}

Kaolin, which is very abundant in nature, is composed of kaolinite, a TO (tetrahedral-octahedral) clay mineral consisting of aluminum and silicon oxides; it also contains some iron, titanium, or manganese impurities as isomorphous substituents in both the octahedral and the tetrahedral layers or as extra framework phases, depending on where the clay originates. However, kaolin does not present good adsorption capacity due to its low cationic exchange capacity (CEC) and specific surface area (SSA) as compared to TOT (tetrahedral-octahedral-tetrahedral) clay minerals and other synthetic materials. Therefore, the synthesis of zeolites from clays such as kaolin is advantageous because zeolites have higher adsorption capacity $[16,17]$. In this context, we aimed to synthesize zeolites starting from two natural clay fractions as precursors, white kaolin and red kaolin (with higher iron content), and to investigate the potential of the resulting zeolites to adsorb the cationic dyes depicted in Table 2.

\section{Experimental}

\subsection{Red and White Kaolin Purification}

The parent clay minerals consisted of red and white kaolins obtained from a deposit in the city of São Simão, state of São Paulo, in the southeast of Brazil. The kaolins were supplied by the mining company Darcy R.O. Silva \& Cia (São Simão-SP, Brazil). The natural clays were purified by the 
dispersion-decantation method. The purified clays were composed of very pure kaolinites and were designated as Ka (derived from white kaolin) and Ka-R (derived from red kaolin).

Table 2. Structures and relevant properties of the cationic dyes used in this work: methylene blue (MB), safranine (SA), and malachite green (MG).

\begin{tabular}{|c|c|c|c|}
\hline Molecule & $\mathrm{MB}$ & SA & MG \\
\hline Molecular dimension $(\AA)$ & $4.22 \times 13.19 \times 5.27$ & $5.11 \times 11.84 \times 10.99$ & $14.41 \times 4.23 \times 12.07$ \\
\hline Molecular surface $\left(\AA^{2}\right)$ & 70 & 130 & 174 \\
\hline C.I. name & Basic blue 9 & Basic red 2 & Basic green 4 \\
\hline C.I. & 52,015 & 50,240 & 42,000 \\
\hline Class & Thiazin & Safranin & Triarylmethane \\
\hline$\lambda_{\max }(\mathrm{nm})$ & 661 & 530 & 614,425 \\
\hline
\end{tabular}

\subsection{Synthesis of Metakaolins}

The purified kaolins Ka and Kao-R were calcined at $600{ }^{\circ} \mathrm{C}$ for $12 \mathrm{~h}$, in air. The resulting metakaolins were designated $\mathrm{M}-\mathrm{Ka}$ and $\mathrm{M}-\mathrm{Ka}-\mathrm{R}$, respectively.

\subsection{Synthesis of Zeolite A}

The zeolites were synthesized through the hydrothermal route, which is a multiphase reaction-crystallization process, as emphasized by several authors [12-15,20]. This process usually encompasses at least one liquid phase as well as both amorphous and crystalline solid phases. Linde zeolite type A (LTA structure) was prepared by alkali treatment of M-Ka and M-Ka-R with aqueous $\mathrm{NaOH} 5 \mathrm{~mol} \cdot \mathrm{L}^{-1}$ solution at a $\mathrm{NaOH} /$ metakaolin molar ratio of $8: 1 ; \mathrm{Al}_{2} \mathrm{Si}_{2} \mathrm{O}_{7}$ was considered the formula of the metakaolins [21]. The mixture was maintained under magnetic stirring and heated at $80{ }^{\circ} \mathrm{C}$ for $24 \mathrm{~h}$. The resulting zeolites were washed with distilled water several times and dried at $110^{\circ} \mathrm{C}$. The zeolites obtained from M-Ka and M-Ka-R were labeled Zeo and Zeo-R, respectively.

\subsection{Characterization Techniques}

Methylene blue (MB) adsorption was used to quantify the CEC and the total SSA of the zeolites. A MB solution was prepared by dissolving $1 \mathrm{~g}$ of MB in $200 \mathrm{~mL}$ of distilled water. In parallel, $50 \mathrm{mg}$ of the oven-dried zeolite was dispersed in $10 \mathrm{~mL}$ of distilled water. Then, consecutive volumes of $0.5 \mathrm{~mL}$ of the MB solution were added to the zeolite dispersion. After addition of each $0.5-\mathrm{mL}$ aliquot of the MB solution, the mixture was homogenized by magnetic stirring for $1 \mathrm{~min}$. Then, a drop was removed from the dispersion and placed onto Fisher brand filter paper, until a permanent blue halo of unadsorbed MB appeared on the filter paper. The SSA was determined from the MB amount required to reach the end-point, according to the equation

$$
\mathrm{CEC}=\frac{[\mathrm{MB}] \times V}{W} \times 100
$$

where CEC is the cation exchange capacity $\left(\mathrm{mEq} \cdot 100 \mathrm{~g}^{-1}\right),[\mathrm{MB}]$ is the MB solution concentration $\left(\mathrm{mEq} \cdot \mathrm{L}^{-1}\right), V(\mathrm{~L})$ is the volume of MB solution used in the analysis, and $W(\mathrm{~g})$ is the mass of zeolite used in the experiment.

The SSA was calculated according to the Hang and Brindley method; Equation (2) was applied [22]

$$
\mathrm{SSA}=F_{M B} \times \mathrm{CEC}
$$


where SSA is the specific surface area $\left(\mathrm{m}^{2} \cdot \mathrm{g}^{-1}\right)$, and $F_{M B}$ is the normalized value of the MB molecule surface area in $\mathrm{m}^{2}$.

Powder X-ray diffraction (PXRD) patterns of non-oriented powder samples were recorded in a Siemens D-500 diffractometer (Siemens España, Madrid, Spain) with Ni-filtered $\mathrm{Cu} \mathrm{K} \alpha$ radiation, working at $40 \mathrm{kV}$ and $30 \mathrm{~mA}$, at a scanning speed of $2^{\circ} / \mathrm{min}$. Element chemical analyses were carried out by inductively coupled plasma-atomic emission spectrometry (ICP-AES) at Activation Laboratories Ltd. (Ancaster, ON, Canada). Infrared (FT-IR) spectra were recorded in the $350-4000 \mathrm{~cm}^{-1}$ range in a Spectrum-One Spectrometer (Perkin-Elmer, Waltham, MA, USA). The KBr pellet technique was employed: about $1 \mathrm{mg}$ of the sample and $300 \mathrm{mg}$ of $\mathrm{KBr}$ were used to prepare the pellets. Thermogravimetric (TG) and differential thermal (DTA) analyses were conducted in a SDT Q600 Simultaneous DTA-TGA-DSC equipment (Thermal Analysis TA, New Castle, PA, USA), from 25 to $900{ }^{\circ} \mathrm{C}$, under nitrogen atmosphere, at a heating rate of $20^{\circ} \mathrm{C} / \mathrm{min}$. The BET specific surface areas were determined from the corresponding nitrogen adsorption data at $-196{ }^{\circ} \mathrm{C}$, measured in an ASAP 2020 analyzer (Micrometrics, Norcross, GA, USA); $0.2 \mathrm{~g}$ of the sample was used. The samples were previously degassed at $200{ }^{\circ} \mathrm{C}$ for $24 \mathrm{~h}$ at a pressure lower than $50 \mu \mathrm{mHg}$. Scanning electron microscopy (SEM) photographs of the materials were obtained in a digital scanning microscope DSM 960 from (Zeiss, Carl Zeiss Iberia-Division Microscopy, Madrid, Spain); the samples had been coated with a thin gold layer by evaporation.

\subsection{Adsorption Experiments}

Equilibrium adsorption experiments were carried out in glass vials by shaking a known amount of the adsorbent, typically $0.1 \mathrm{~g}$, with $5.0 \mathrm{~mL}$ of each dye solution at a given concentration, typically in the 0.14-1 $\mathrm{mmol} \cdot \mathrm{L}^{-1}$ range. After shaking for $30 \mathrm{~min}$, a time selected from previous kinetic experiments, the solid phase was separated via centrifugation at $3500 \mathrm{rpm}$. The dye concentration in the solution was determined by UV-vis spectroscopy in a Hewlett-Packard 8453 Diode Array spectrometer (Agilent Technologies Spain, Madrid), and the amount of adsorbed dye was calculated by means of Equation (3)

$$
q_{e}=\frac{\left(C_{0}-C_{e}\right) \times V}{m}
$$

where $q_{e}\left(\mathrm{mmol} \cdot \mathrm{g}^{-1}\right)$ is the amount of adsorbed dye; $C_{i}$ and $C_{e}\left(\mathrm{mmol} \cdot \mathrm{L}^{-1}\right)$ are the initial and equilibrium liquid-phase concentrations of the dye, respectively; $V(\mathrm{~L})$ is the volume of the solution; and $m(\mathrm{~g})$ is the amount of adsorbent used in the experiment.

$\mathrm{NaOH}$ was supplied by Labsynth Products Laboratories (Diadema, Brazil). The other reagents used in the preparation and characterization of the zeolites and in adsorption experiments were purchased from Sigma-Aldrich ${ }^{\circledR}$ (Madrid, Spain) and had the highest purity, so they were used without purification. The gases were obtained from Oxi-Franca (Franca, Brazil).

\section{Results and Discussion}

\subsection{Preparation and Characterization of the Materials}

Table 3 lists the chemical composition of the parent kaolins Ka and Ka-R, which have very similar composition. Ka-R has slightly higher amounts of $\mathrm{Fe}_{2} \mathrm{O}_{3}$ and $\mathrm{MnO}$ than $\mathrm{Ka}$. Clays usually have the reddish/brownish/yellowish color pattern on the surface of aggregates, on pore surfaces, and in the upper soil horizons as a result of oxidized transition metals such as $\mathrm{Fe}^{3+}$ and $\mathrm{Mn}^{4+}$. The grayish/bluish colors of clays appear within aggregates or in the deeper soil horizons and are due to $\mathrm{Fe}^{2+}$ and $\mathrm{Mn}^{2+}$ cations present in the layers. The $\mathrm{Fe}^{3+}$ and $\mathrm{Mn}^{2+} / \mathrm{Mn}^{4+}$ contents may justify the differences between the colors of $\mathrm{Ka}$ and $\mathrm{Ka}-\mathrm{R}$ and should influence their reactivity depending on whether $\mathrm{Fe}^{3+}$ and $\mathrm{Mn}^{2+} / \mathrm{Mn}^{4+}$ are present as extra framework phases or if they are located in structural positions.

The X-ray powder diffraction patterns of the zeolites Zeo and Zeo-R synthesized from the metakaolins M-Ka and M-Ka-R (Figure 1) reveal the presence of a single and very pure phase. Comparison with the 
JCPDS file 43-142 clearly shows that Zeo and Zeo-R are hydrated Linde Type Zeolite A (LTA). LTA has a three-dimensional pore structure where the pores are perpendicular to each other along the $x, y$, and $z$ directions. The pore diameter is defined by a small ring $(4.2 \AA)$ of eight oxygen atoms, which gives a large cavity with free diameter of $11.4 \AA$. The unit cell is cubic (a: $24.64 \AA$ ).

Table 3. Chemical composition (wt \%) of the parent purified kaolins (Ka and Ka-R) and of the obtained zeolites (Zeo and Zeo-R), expressed on a dry basis (metal oxides 100\%).

\begin{tabular}{cccccccccc}
\hline Sample & $\mathrm{SiO}_{2}$ & $\mathrm{Al}_{2} \mathbf{O}_{3}$ & $\mathrm{Fe}_{2} \mathbf{O}_{3}$ & $\mathbf{M n O}$ & $\mathbf{M g O}$ & $\mathbf{C a O}$ & $\mathbf{N a}_{2} \mathbf{O}$ & $\mathbf{K}_{2} \mathbf{O}$ & $\mathrm{TiO}_{2}$ \\
\hline $\mathrm{Ka}$ & 54.24 & 42.61 & 1.51 & 0.005 & 0.15 & 0.04 & 0.02 & 0.41 & 1.01 \\
$\mathrm{Ka}-\mathrm{R}$ & 54.06 & 42.60 & 1.59 & 0.010 & 0.18 & 0.13 & 0.02 & 0.41 & 1.00 \\
$\mathrm{Zeo}$ & 43.52 & 34.39 & 0.67 & 0.005 & 0.11 & 0.03 & 20.59 & 0.14 & 0.55 \\
$\mathrm{Zeo}-\mathrm{R}$ & 44.35 & 33.82 & 0.96 & 0.006 & 0.11 & 0.02 & 19.82 & 0.26 & 0.66 \\
\hline
\end{tabular}
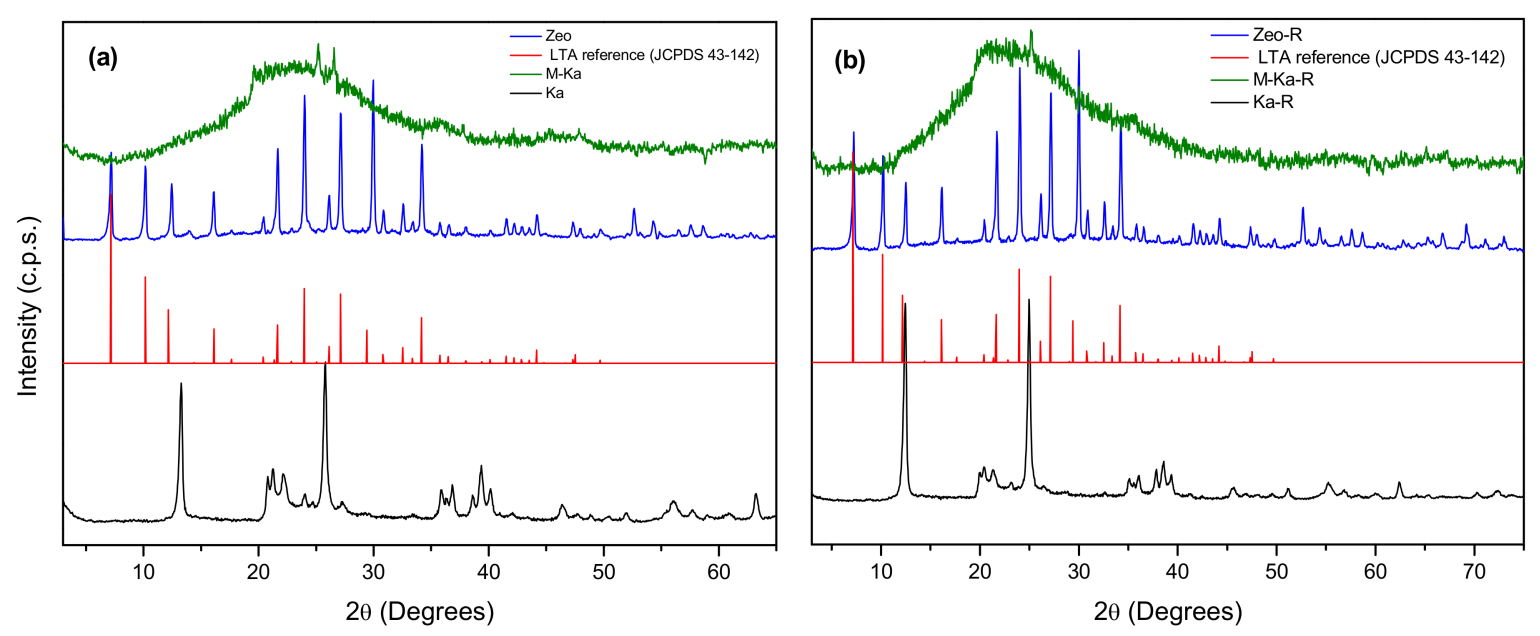

Figure 1. PXRD patterns of the purified parent kaolins Ka and Ka-R, the metakaolins M-Ka and M-Ka-R, and the synthesized zeolites Zeo and Zeo-R, prepared from white (a) and red (b) kaolins, respectively.

The purity of zeolites synthesized from kaolin has been reported to depend on various factors such as $\mathrm{NaOH}$ concentration, $\mathrm{Al} / \mathrm{Si}$ ratio, calcination temperature of the parent kaolin, and duration of the treatment [12]. Here, the powder X-ray diffractograms prove that the small differences in Fe and Mn contents do not interfere in the synthesis of zeolite A: there is only a small decrease in the reflection intensities of the sample Zeo-R, in agreement with literature results. This decrease indicates the presence of isomorphic substituents in the clay mineral, which may lower the crystallinity of the resulting zeolite [15].

Thermogravimetric analyses (Figure 2) of the zeolites Zeo and Zeo-R give rise to more complex curves than the curves of the parent kaolins, Ka and Ka-R (not included, but typical of this mineral). Mass loss reaches values close to $23 \%$ for both Zeo and Zeo-R, which are very close to the expected value for zeolite A. The theoretical mass loss for a 'typical' zeolite A, with formula $\mathrm{Na}_{12} \mathrm{Al}_{12} \mathrm{Si}_{12} \mathrm{O}_{48} \cdot 27 \mathrm{H}_{2} \mathrm{O}$, is $22.2 \%$, but the mass loss strongly depends on the storage conditions. In the present case, special storage conditions were not adopted, so both zeolites Zeo and Zeo-R may have a low amount of adsorbed water. Water removal is almost complete around a temperature of $250{ }^{\circ} \mathrm{C}$. The DTG curves (not shown) demonstrate that this removal occurs in three consecutive, overlapped processes centered at $65-70,120-150$, and $220-240{ }^{\circ} \mathrm{C}$, which correspond to water held to the zeolite at various strengths, adsorbed water, and zeolitic water, respectively. Zeo- $\mathrm{R}$ undergoes a small additional mass loss at ca. $350{ }^{\circ} \mathrm{C}$, which may be related to the removal of $\mathrm{CO}_{2}$ fixed as carbonate during the preparation 
procedure in a strongly basic solution. At higher temperatures, dehydroxylation can be detected as a gentle, continuous mass decrease [23].
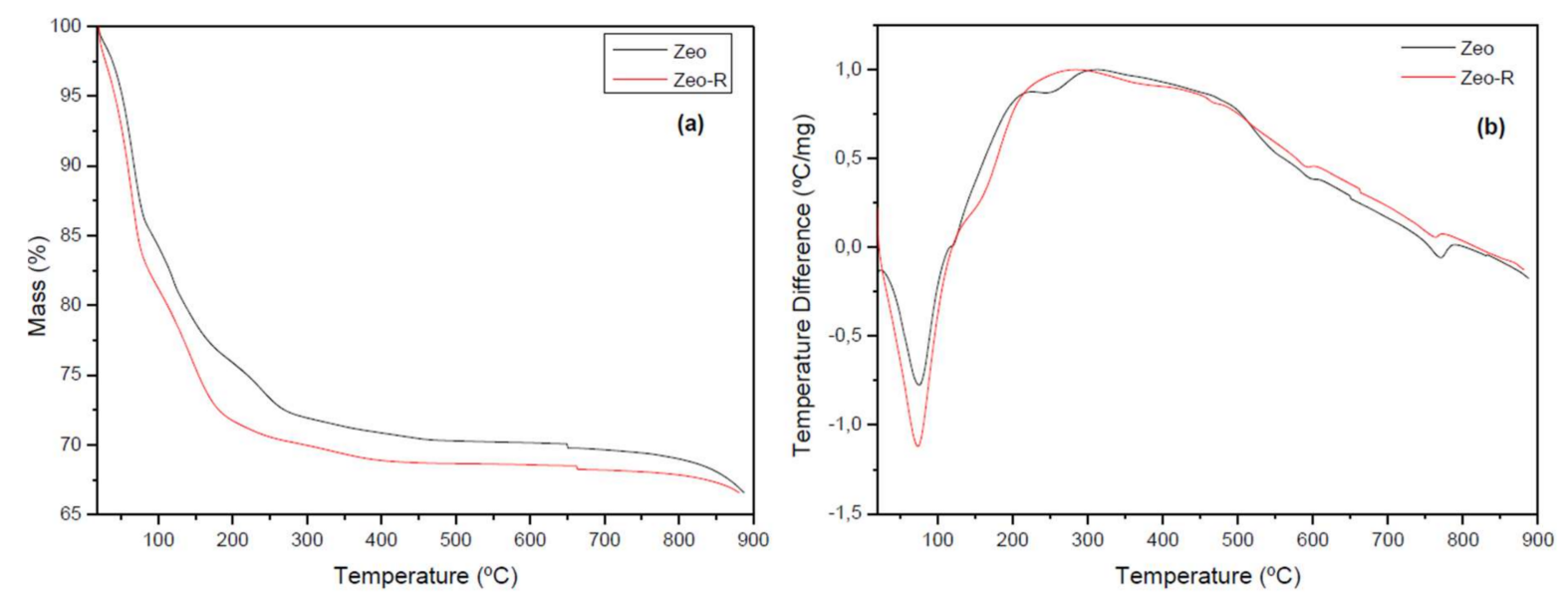

Figure 2. Thermogravimetric (a) and differential thermal (b) analysis curves of the zeolites prepared from white and red kaolins.

The nitrogen adsorption/desorption isotherms on the samples measured at $-196{ }^{\circ} \mathrm{C}$ refer to type II isotherms (IUPAC classification [24]). This type of isotherm evidences that a complex structure with undefined pore size and volume size distributions exists due to low adsorption values (Figure 3). The BET SSA values follow the same trend in both series, increasing when one goes from kaolin to metakaolin and strongly decreasing when one goes from metakaolin to zeolite (Table 4). The increase from kaolin to metakaolin can be related to amorphization induced by calcination of kaolin to form metakaolin (see Figure 1). The sharp decrease from metakaolin to zeolite may be due to the extremely high crystallinity of the zeolite particles and their large particle size, as suggested by X-ray diffraction and confirmed by electron microscopy (vide infra). Given the large crystal size, the SSA is almost exclusively due to contribution from the external surface. In the same way, the pore size decreases when one goes from kaolin to metakaolin and increases when one goes from metakaolin to zeolite (Table 4).
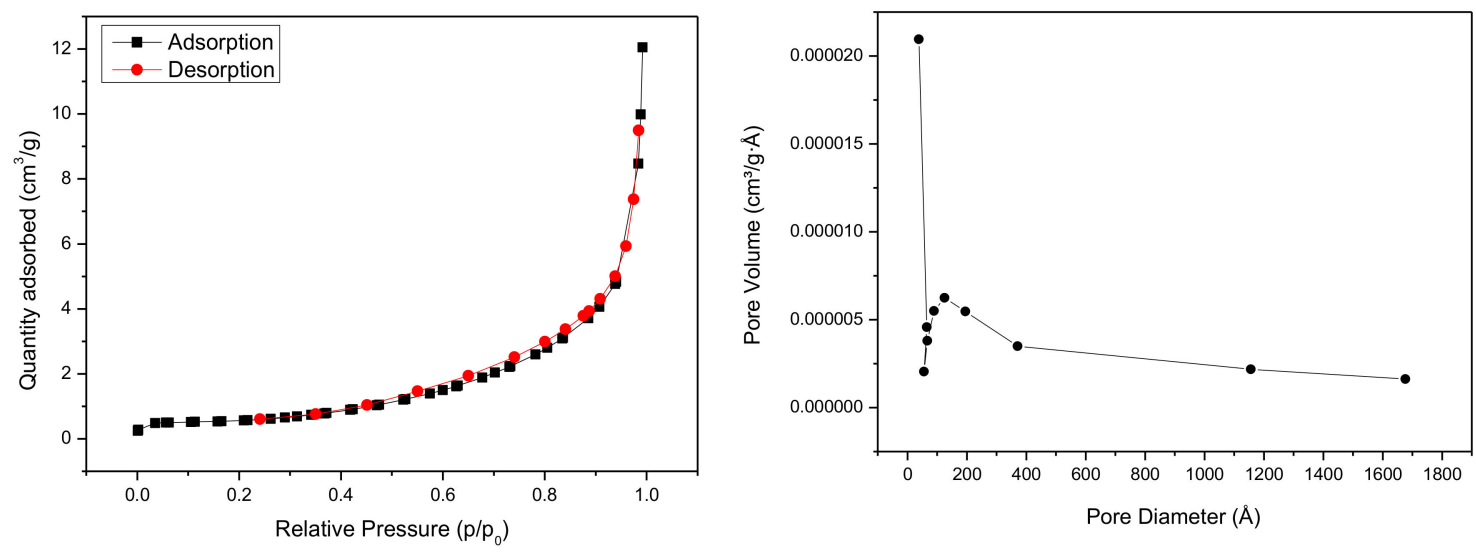

Figure 3. $\mathrm{N}_{2}$ adsorption-desorption isotherm at $-196{ }^{\circ} \mathrm{C}$ and $\mathrm{BJH}$ pore size distribution for the zeolite Zeo, derived from white kaolin. 
Table 4. CEC and BET specific surface areas for the precursors Ka, Ka-R, M-Ka, and M-Ka-R; and the final zeolites Zeo and Zeo-R.

\begin{tabular}{|c|c|c|c|c|c|}
\hline Sample & MB Saturation Volume (mL) & CEC $\left(\mathrm{mEq} \cdot 100 \mathrm{~g}^{-1}\right)$ & $\operatorname{CEC~SSA~}^{1}\left(\mathrm{~m}^{2} \cdot \mathrm{g}^{-1}\right)$ & BET SSA $^{2}\left(m^{2} \cdot g^{-1}\right)$ & Pore Size (̊̊) \\
\hline $\mathrm{Ka}$ & 0.40 & 8.0 & 62 & 15 & 179 \\
\hline M-Ка & 0.15 & 3.0 & 23 & 69 & 110 \\
\hline Zeo & 0.40 & 8.0 & 62 & 2 & 355 \\
\hline Ka-R & 0.30 & 6.0 & 47 & 16 & 184 \\
\hline M-Ka-R & 0.10 & 2.0 & 16 & 79 & 113 \\
\hline Zeo-R & 0.25 & 5.0 & 39 & 1 & 1130 \\
\hline
\end{tabular}

Table 4 also provides the CEC SSA values regarding MB adsorption. In this case, CEC SSA decreases when one goes from kaolin to metakaolin and increases when one goes from metakaolin to zeolite. The CEC SSA values of the zeolites are very close to the CEC SSA values of the original kaolins. The CEC SSA values of Zeo and Zeo-R do not differ, which demonstrates that the slight differences in crystallinity do not affect CEC SSA. The results suggest that the CEC SSA of the kaolins Ka and Ka-R, which are originally rather low, decrease due to the strong calcination conditions applied to obtain the metakaolins, M-Ka and Me-Ka-R. Further reaction to produce the zeolites recovers the CEC SSA in the final Zeo and Zeo-R despite their large particle size and high crystallinity. However, the low surface area of the zeolites and the difficult access to their pores indicate that the experimental values may be affected by $\mathrm{MB}$ aggregation depending on the $\mathrm{pH}$ of the dispersions, to culminate in the large difference between the SSA values of the gas and liquid phase media.

The micrographs in Figure 4 depict the typical morphology of the very fine and rigid kaolinite particles. Stacked sheets forming tactoids, which produce aggregates, are evident. The micrographs of Zeo and Zeo-R reveal the formation of large cubic crystals, a typical morphology of these solids [25]. The shape of these crystals depends not only on the chemical composition of the zeolite, but also on the conditions used during the synthesis. In the current case, the morphology of the Zeo and Zeo-R crystals is very close to cubic. Zeo-R is more regular than Zeo. Aggregation of cubic crystal clusters gives quasi-spherical aggregates, an effect that is more evident for Zeo.

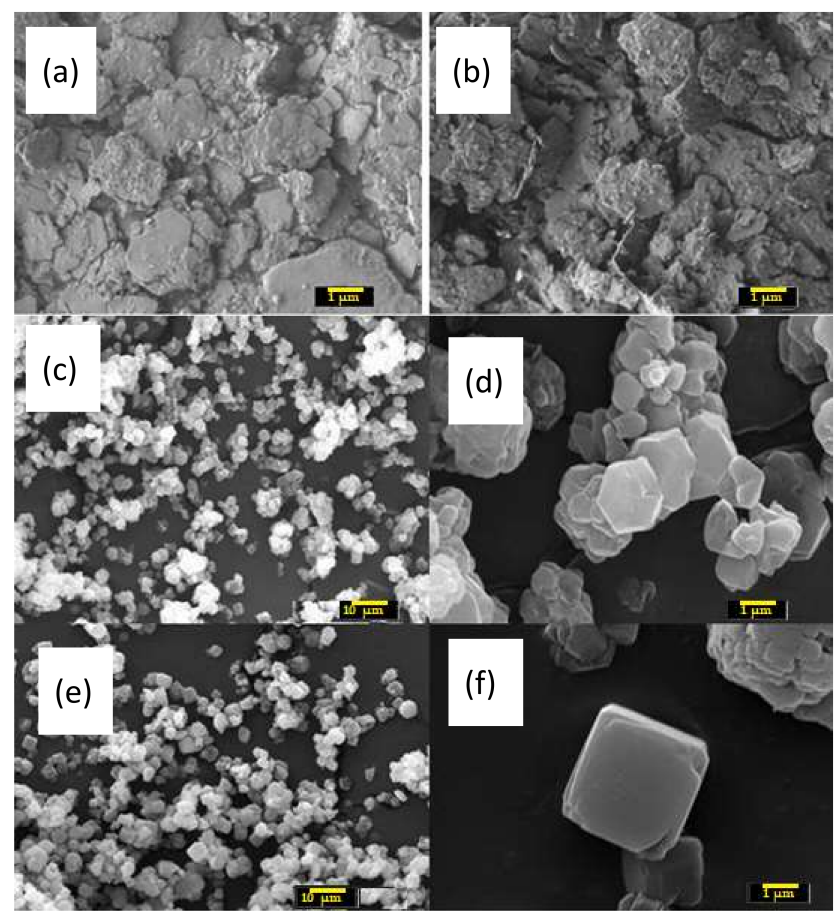

Figure 4. SEM micrographs of purified white kaolin (a) and red kaolin (b), Zeo zeolite (c,d) and Zeo-R zeolite $(\mathbf{e}, \mathbf{f})$. 


\subsection{Adsorption Studies}

Equilibrium data, commonly denoted as adsorption isotherm, are important to define the mechanism of the adsorption process accurately [26]. Here, the Langmuir, Freundlich, and Sips isotherm models were used to analyze the adsorption of dyes onto Zeo and Zeo-R.

Figure 5 illustrates fitting of the experimental adsorption data with the aforementioned models. According to the Giles classification [27], the isotherms are type L-2 when MB and SA are tested as adsorbates, and type S-2 when MG is tested as adsorbate. L-type isotherms are characterized by a non-linear convex curve, which indicates lower availability of adsorption sites as the concentration at equilibrium increases and high affinity of the adsorbate for the adsorbent. As for S-type isotherms, the adsorption capacity of the solid increases as the adsorbate concentration rises.

Table 5 summarizes the parameters obtained from the nonlinear plots of each isotherm. Fitting of the models to the experimental data was evaluated by the chi-square test $\left(\chi^{2}\right)$ and the coefficient of determination $(R)$. Most of the $R$ values exceed 0.9 for the Langmuir model, which suggests that the model could fit the experimental results.
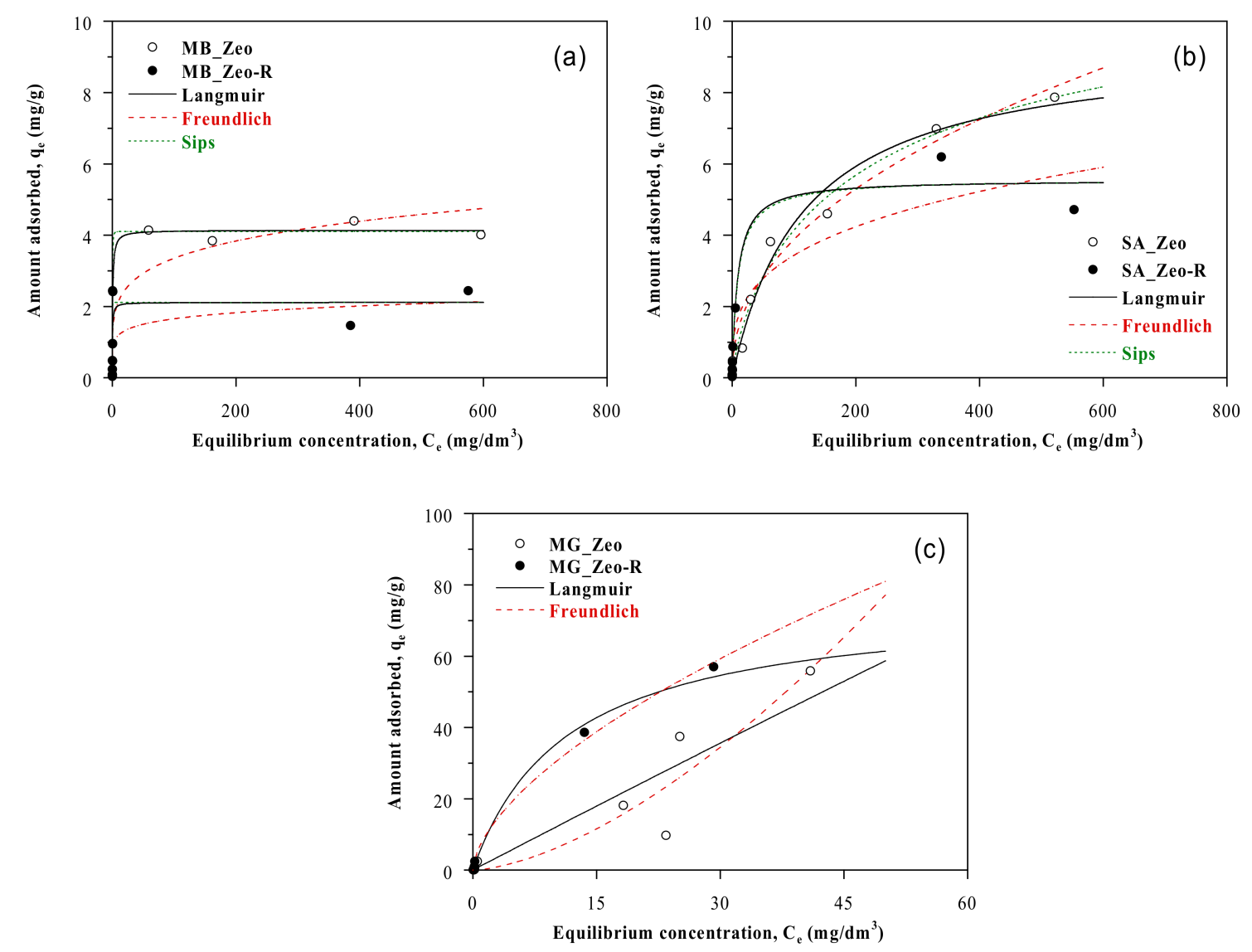

Figure 5. Equilibrium adsorption data for Zeo and Zeo-R as adsorbents and MB (a), SA (b), and MG (c) dyes as adsorbates.

The $k_{L}$ values for the Langmuir model vary between 2.4 and $0.0006 \mathrm{~L} / \mathrm{mg}$. The $k_{L}$ values are different when we compare the adsorption of dyes onto Zeo and Zeo-R (e.g., 2.4 and $1.4 \mathrm{~L} / \mathrm{mg}$ for MB, respectively). Therefore, the adsorption capacity of the zeolites depends on the precise kaolin that is used as precursor for the synthesis of zeolites.

The decrease in the $k_{L}$ values could be related to molecular volume and steric hindrance. This is not surprising because zeolite $A$ has a narrow pore aperture, which makes access very difficult for the dye molecules [28]. The results indicate that the affinity of the binding sites in Zeo-R increases for 
all the dyes probably because there are isomorphic substitutions in the parent kaolin. The $k_{L}$ values vary between zero and 0.11 for SA adsorption onto Zeo and Zeo-R, suggesting that this dye has large affinity for solids.

As previously reported by some authors, zeolite materials generally display high affinity for cationic dyes with very small molecular size, such as methylene blue. The behavior of MG, MB, and SA adsorption onto Zeo and Zeo-R shows that both zeolites have more affinity for MB, the dye with the smallest molecular size. Other authors have reported efficient removal of cationic dyes like basic blue 17 , basic red 46 , basic green 4 , basic blue 9 , basic violet 10 , and basic yellow 28 by natural zeolites (e.g., clinoptilolite) [29-33]. In contrast, adsorption studies of anionic, acid dyes are very limited, and very low adsorption capacity values $\left(0.5 \mathrm{mg} \mathrm{g}^{-1}\right)$ have been reported [18,34].

Table 5. Langmuir, Freundlich, and Sips equation parameters for the adsorption of MB, SA, and MG onto Zeo and Zeo-R.

\begin{tabular}{|c|c|c|c|c|c|c|}
\hline Dye-Adsorbent & MB-Zeo & MB-Zeo-R & SA-Zeo & SA-Zeo-R & MG-Zeo & MG-Zeo-R \\
\hline \multicolumn{7}{|l|}{ Langmuir ${ }^{\mathrm{a}}$} \\
\hline$q_{L}(\mathrm{mg} / \mathrm{g})$ & 4.1 & 2.1 & 9.4 & 5.5 & 2094 & 75 \\
\hline$k_{L}(\mathrm{~L} / \mathrm{mg})$ & 1.4 & 2.4 & 0.0086 & 0.11 & 0.00057 & 0.087 \\
\hline$x^{2}$ & 0.83 & 1.94 & 1.4 & 1.2 & 462 & 14 \\
\hline$R$ & 0.98 & 0.85 & 0.991 & 0.98 & 0.93 & 0.997 \\
\hline \multicolumn{7}{|l|}{ Freundlich ${ }^{b}$} \\
\hline$k_{F}(\mathrm{~L} / \mathrm{g})$ & 1.4 & 0.86 & 0.49 & 0.85 & 0.16 & 7.4 \\
\hline $\mathrm{m}_{\mathrm{F}}$ & 5.2 & 7.1 & 2.2 & 3.3 & 0.63 & 1.6 \\
\hline$x^{2}$ & 4.8 & 3.7 & 1.5 & 3.4 & 327 & 14 \\
\hline$R$ & 0.92 & 0.68 & 0.990 & 0.95 & 0.95 & 0.998 \\
\hline \multicolumn{7}{|l|}{ Sips ${ }^{c}$} \\
\hline$q_{s}(\mathrm{mg} / \mathrm{g})$ & 4.1 & 2.1 & 12 & 5.6 & - & - \\
\hline$k_{S}(\mathrm{~L} / \mathrm{mg})$ & 4.7 & 752 & 0.015 & 0.12 & - & - \\
\hline$m_{S}$ & 2.2 & 9.4 & 0.76 & 0.95 & - & - \\
\hline$x^{2}$ & 0.34 & 0.91 & 1.2 & 1.2 & - & - \\
\hline$R$ & 0.995 & 0.93 & 0.992 & 0.98 & - & - \\
\hline
\end{tabular}

${ }^{\text {a }}$ Langmuir equation isotherm: $q_{e}=\frac{q_{L} \cdot k_{L} \cdot C_{e}}{1+k_{L} \cdot C_{e}} ;{ }^{b}$ Freundlich equation isotherm: $q_{e}=k_{F} \cdot C_{e}{ }^{1 / m_{F}} ;{ }^{c}$ Sips equation isotherm: $q_{e}=\frac{q_{S} \cdot k_{S} \cdot C_{e} m_{S}}{1+k_{S} \cdot C_{e} 1 / m_{S}}$.

\section{Conclusions}

Zeolites obtained from kaolins efficiently adsorb methylene blue, safranine, and malachite green from aqueous solutions. The molecular volume of the dyes influences the adsorption capacity of zeolites and alters the adsorption rate calculated by theoretical kinetic and equilibrium models. In addition, the synthesized zeolites could have their adsorption capacity limited by the presence of cations and water molecules in their pores, which could block the access of larger molecules such as dyes. Overall, taking green chemistry requirements into account, zeolites prepared from natural clays are promising materials for the removal of many environmental pollutants.

Acknowledgments: The Spanish authors thank the Spanish Ministry of Economy and Competitiveness (MINECO) and the European Regional Development Fund (ERDF) for joint financial support (grant MAT2013-47811-C2-R and MAT2016-78863-C2-R). The Brazilian group acknowledges the support from the Brazilian research funding agencies Fundação de Amparo à Pesquisa do Estado de São Paulo (FAPESP) (311767/2015-0, 2012/08618-0, 2013/19523-3, and 2016/01501-1), Coordenação de Aperfeiçoamento de Pessoal de Nível Superior (CAPES), and Conselho Nacional de Desenvolvimento Científico e Tecnológico (CNPq). Both groups thank the Spain-Brazil Interuniversity Cooperation Grant, jointly funded by the Spanish Ministry of Education, Science and Sports (PHBP14/00003) and CAPES (317/15).

Author Contributions: E.J. Nassar, K.J. Ciuffi, M.A. Vicente, R. Trujillano, V. Rives, A. Gil, S. Korili and E.H. de Faria conceived, designed and guided the experiments; P.M. Pereira, B.F. Ferreira and N.P. Oliveira prepared the materials; all the authors participated in the characterization of the materials; P.M. Pereira, B.F. Ferreira and N.P. Oliveira wrote 
the first version of the manuscript; E.J. Nassar, K.J. Ciuffi, M.A. Vicente, R. Trujillano, V. Rives, A. Gil, S. Korili and E.H. de Faria revised/discussed the manuscript.

Conflicts of Interest: The authors declare no conflict of interest.

\section{References}

1. Fatima, M.; Farooq, R.; Lindström, R.W.; Saeed, M. A review on biocatalytic decomposition of azo dyes and electrons recovery. J. Mol. Liq. 2017, 246, 275-281. [CrossRef]

2. Kumar, S.S.; Shantkriti, S.; Muruganandham, T.; Murugesh, E.; Rane, N.; Govindwar, S.P. Bioinformatics aided microbial approach for bioremediation of wastewater containing textile dyes. Ecol. Inform. 2016, 31, 112-121.

3. Jawale, R.H.; Tandale, A.; Gogate, P.R. Novel approaches based on ultrasound for treatment of wastewater containing potassium ferrocyanide. Ultrason. Sonochem. 2017, 38, 402-409. [CrossRef] [PubMed]

4. Wong, S.; Yac'cob, N.A.N.; Ngadi, N.; Hassan, O.; Inuwa, I.M. From Pollutant to Solution of Wastewater Pollution: Synthesis of Activated Carbon from Textile Sludge for Dyes Adsorption. Chin. J. Chem. Eng. 2017, in press. [CrossRef]

5. Shen, T.; Wang, Q.; Tong, S. Solid Base MgO/Ceramic Honeycomb Catalytic Ozonation of Acetic Acid in Water. Ind. Eng. Chem. Res. 2017, 56, 10965-10971. [CrossRef]

6. $\quad$ Liang, C.Z.; Sun, S.P.; Li, F.Y.; Ong, Y.K.; Chung, T.S. Treatment of highly concentrated wastewater containing multiple synthetic dyes by a combined process of coagulation/flocculation and nanofiltration. J. Membr. Sci. 2014, 469, 306-315. [CrossRef]

7. Edebali, S.; Pehlivan, E. Evaluation of chelate and cation exchange resins to remove copper ions. Powder Technol. 2016, 301, 520-525. [CrossRef]

8. Tan, L.; Shuang, C.; Wang, Y.; Wang, J.; Su, Y.; Li, A. Effect of pore structure on the removal of clofibric acid by magnetic anion exchange resin. Chemosphere 2018, 191, 817-824. [CrossRef] [PubMed]

9. Chitpong, N.; Husson, S.M. High-capacity, nanofiber-based ion-exchange membranes for the selective recovery of heavy metals from impaired waters. Sep. Purif. Technol. 2017, 179, 94-103. [CrossRef]

10. Huang, Z.; Li, Y.; Chen, W.; Shi, J.; Zhang, N.; Wang, X.; Li, Z.; Gao, L.; Zhang, Y. Modified bentonite adsorption of organic pollutants of dye wastewater. Mater. Chem. Phys. 2017, 202, 266-276. [CrossRef]

11. Dong, W.; Li, W.; Yu, K.; Krishna, K.; Song, L.; Wang, X.; Wang, Z.; Coppens, M.O.; Feng, S. Synthesis of silica nanotubes from kaolin clay. Chem. Commun. 2003, 1302-1303. [CrossRef]

12. Belver, C.; Vicente, M.A. Easy Synthesis of K-F Zeolite from Kaolin, and Characterization of This Zeolite. J. Chem. Educ. 2006, 83, 1541-1542. [CrossRef]

13. Belver, C.; Bañares Muñoz, M.A.; Vicente, M.A. Chemical activation of a kaolinite under acid and alkaline conditions. Chem. Mater. 2002, 14, 2033-2043. [CrossRef]

14. Selim, M.M.; El-Mekkawi, D.M.; Aboelenin, R.M.M.; Sayed Ahmed, S.A.; Mohamed, G.M. Preparation and characterization of Na-A zeolite from aluminum scrub and commercial sodium silicate for the removal of $\mathrm{Cd}^{2+}$ from water. J. Assoc. Arab Univ. Basic Appl. Sci. 2017, 24, 19-25. [CrossRef]

15. Basaldella, E.I.; Sánchez, R.M.T.; Tara, J.C. Iron influence in the aluminosilicate zeolites synthesis. Clays Clay Miner. 1998, 46, 481-486. [CrossRef]

16. Xu, H.Y.; Wu, L.C.; Shi, T.N.; Liu, W.C.; Qi, S.Y. Adsorption of acid fuchsin onto LTA-type zeolite derived from fly ash. Sci. China Technol. Sci. 2014, 57, 1127-1134. [CrossRef]

17. Tümsek, F.; Avc1, Ö. Investigation of Kinetics and Isotherm Models for the Acid Orange 95 Adsorption from Aqueous Solution onto Natural Minerals. J. Chem. Eng. Data 2013, 58, 551-559. [CrossRef]

18. Hernández-Montoya, V.; Pérez-Cruz, M.A.; Mendoza-Castillo, D.I.; Moreno-Virgen, M.R.; Bonilla-Petriciolet, A. Competitive adsorption of dyes and heavy metals on zeolitic structures. J. Environ. Manag. 2013, 116, 213-221. [CrossRef] [PubMed]

19. Loannou, Z.; Karasawidis, C.; Dimirkou, A.; Antoniadis, V. Adsorption of methylene blue and methyl red dyes from aqueous solutions onto modified zeolites. Water Sci. Technol. 2013, 67, 1129-1136.

20. Nassar, M.Y.; Abdelrahman, E.A. Hydrothermal tuning of the morphology and crystallite size of zeolite nanostructures for simultaneous adsorption and photocatalytic degradation of methylene blue dye. J. Mol. Liq. 2017, 242, 364-374. [CrossRef] 
21. El-Mekkawi, D.M.; Ibrahim, F.A.; Selim, M.M. Removal of methylene blue from water using zeolites prepared from Egyptian kaolins collected from different sources. J. Environ. Chem. Eng. 2016, 4, 1417-1422. [CrossRef]

22. Maček, M.; Mauko, A.; Mladenovič, A.; Majes, B.; Petkovšek, A. A comparison of methods used to characterize the soil specific surface area of clays. Appl. Clay Sci. 2013, 83-84, 144-152. [CrossRef]

23. Musyoka, N.M.; Petrik, L.F.; Hums, E.; Kuhnt, A.; Schwieger, W. Thermal stability studies of zeolites A and X synthesized from South African coal fly ash. Res. Chem. Intermed. 2015, 41, 575-582. [CrossRef]

24. Sing, K.S.W. Reporting physisorption data for gas/solid systems with special reference to the determination of surface area and porosity (Recommendations 1984). Pure Appl. Chem. 1985, 57, 603-619. [CrossRef]

25. Zide, D.; Fatoki, O.; Oputu, O.; Opeolu, B.; Nelana, S.; Olatunji, O. Zeolite "adsorption" capacities in aqueous acidic media; The role of acid choice and quantification method on ciprofloxacin removal. Microporous Microporous Mater. 2018, 255, 226-241. [CrossRef]

26. Moreira, M.A.; Ciuffi, K.J.; Rives, V.; Vicente, M.A.; Trujillano, R.; Gil, A.; Korili, S.A.; de Faria, E.H. Effect of chemical modification of palygorskite and sepiolite by 3-aminopropyltriethoxisilane on adsorption of cationic and anionic dyes. Appl. Clay Sci. 2017, 135, 394-404. [CrossRef]

27. Giles, C.H.; Smith, D.; Huitson, A. A General Treatment and Classification of the Solute Adsorption Isotherm. I. Theoretical. J. Colloid Interface Sci. 1974, 47, 766-778. [CrossRef]

28. Awala, H.; Leite, E.; Saint-Marcel, L.; Clet, G.; Retoux, R.; Naydenova, I.; Mintova, S. Properties of methylene blue in the presence of zeolite nanoparticles. New J. Chem. 2016, 40, 4277-4284. [CrossRef]

29. Alpat, S.K.; Özbayrak, Ö.; Alpat, S.; Akçay, H. The adsorption kinetics and removal of cationic dye, Toluidine Blue O, from aqueous solution with Turkish zeolite. J. Hazard. Mater. 2008, 151, 213-220. [CrossRef] [PubMed]

30. Karadag, D.; Turan, M.; Akgul, E.; Tok, S.; Faki, A. Adsorption equilibrium and kinetics of reactive black 5 and reactive red 239 in aqueous solution onto surfactant-modified zeolite. J. Chem. Eng. Data 2007, 52, 1615-1620. [CrossRef]

31. Wang, S.; Ariyanto, E. Competitive adsorption of malachite green and Pb ions on natural zeolite. J. Colloid Interface Sci. 2007, 314, 25-31. [CrossRef] [PubMed]

32. Wang, S.; Zhu, Z.H. Characterisation and environmental application of an Australian natural zeolite for basic dye removal from aqueous solution. J. Hazard. Mater. 2006, 136, 946-952. [CrossRef] [PubMed]

33. Yener, J.; Kopac, T.; Dogu, G.; Dogu, T. Adsorption of Basic Yellow 28 from aqueous solutions with clinoptilolite and amberlite. J. Colloid Interface Sci. 2006, 294, 255-264. [CrossRef] [PubMed]

34. Jin, X.; Jiang, M.Q.; Shan, X.Q.; Pei, Z.G.; Chen, Z. Adsorption of methylene blue and orange II onto unmodified and surfactant-modified zeolite. J. Colloid Interface Sci. 2008, 328, 243-247. [CrossRef] [PubMed] 